\title{
EDMED INCONEL 718 USING POWDER METALLURGY (P/M) SINTERED ELECTRODE MADE WITH NANO AND MICRON SIZED POWDERS
}

\author{
R.V.S. Subrahmanyam ${ }^{{ }^{*}}$ - Ramji Koona ${ }^{1}$ - Srinivasa Rao Pujari ${ }^{2}$
}

${ }^{1}$ Mechanical Engineering, College of Engineering, Andhra University, Visakhapatnam, India

${ }^{2}$ Mechanical Engineering, Institute of Technology, GITAM, Visakhapatnam, India

\begin{tabular}{l} 
ARTICLE INFO \\
\hline Article history: \\
Received: 28.6 .2018$. \\
Received in revised form: 30.10 .2018$. \\
Accepted: 8.11 .2018$. \\
\hline Keywords: \\
Surface modification \\
Surface Roughness \\
Micro Hardness \\
P/M Electrode \\
\hline DOI: http://doi.org/10.30765/er.40.3.06
\end{tabular}

\section{Introduction}

Inconel 718 has wide applications in aviation, medical and chemical industries due to their excellent mechanical properties viz. resistance to fatigue, corrosion, and creep [1-2]. At elevated temperatures, however, it is very difficult for a machine to use

\begin{abstract}
:
This work presents experimental data carried out for surface modification of Inconel 718 using $W C / C u$ composite powder metallurgy (P/M) electrodes made of nano and micron sized particles. Both machine and tool parameters were selected for study and experiments were planned as per Taguchi's L18 mixed orthogonal array in order to find the influence of parameters on surface roughness (SR) and micro-hardness (MH). Peak current, particle size and pulse on time were found to be most significant on both SR and MH. High reactive surface area of nano particles made surface alloying greater than the other tool electrodes and has shown its influence positively on both SR and MH. The EDX analysis reveals the migration of $\mathrm{WC}$ and $\mathrm{Cu}$ elements and deposition of carbon and oxygen particles on the surface. The XRD spectrum confirms presence of carbides (WC, $\mathrm{W}_{2} \mathrm{C}, \mathrm{Fe}_{5} \mathrm{C}_{2}, \mathrm{Cr}_{7} \mathrm{C}_{3}, \mathrm{Fe}_{7} \mathrm{C}_{3}$ and $\mathrm{Fe}_{3} \mathrm{C}$ ), oxides $\left(\mathrm{Fe}_{3} \mathrm{O}_{4}, \mathrm{WO}_{3}\right.$ and $\left.\mathrm{Cr}_{3} \mathrm{O}\right)$ and other intermetallics at different machining conditions indicating the influence of Pulse on time (TON) and Peak current (IP) on discharge energies and in turn on the properties of machined surface. The carbides generated on the machined surface increased the hardness to $845 H V$ without much sacrifice of the roughness of the machined surface. The range of roughness values obtained in the present investigation is 2.443 to $4.098 \mu \mathrm{m}$.
\end{abstract}

conventional cutting and grinding because of its high strength. But its poor machinability is due to lower elastic modulus and thermal conductivity making it unsuitable for conventional machining processes [35]. In addition, its abrasive and adhesive wear characteristics are also inferior, thus necessitating the surface modification processes [6-7]. Surface

\footnotetext{
* Corresponding author.

E-mail address: rrss1961@gmail.com
} 
modification was identified, through migration of materials from tool to work surface, as one of the key manufacturing processes in aerospace, marine, and biomechanical industries. Electric discharge machining (EDM) is one of the unconventional machining processes commonly used for machining difficult to cut materials, which are used nowadays for obtaining the desired properties of the machined sample through surface modification. In this process, a series of discrete electrical discharges occur between tool and work piece electrodes which are immersed in a dielectric fluid. Due to high temperatures generated during the process, it melts and partially vaporizes the material at the point of discharge [8-10]. A material removal takes place from both the electrodes in which a part of molten metal from the electrode and constituents of the dielectric migrate and deposit on the work piece. Surface modification is necessary to improve hardness resistance to wear, corrosion, fatigue, etc. The commonly used materials for EDM electrodes are copper and its alloys, brass, zinc, tungsten and graphite. Each material has its own advantages and disadvantages. So the unavailability of single tool material for combination of the desirable properties of the machined surface, points towards powder metallurgy $(\mathrm{P} / \mathrm{M})$ tool electrodes. It is proved that $\mathrm{P} / \mathrm{M}$ electrodes were technically viable and the properties of electric discharge machined (EDMed) surface can be improved by changing electrode and machining parameters [11].

In view of that, researchers used different EDM electrodes made out of $\mathrm{P} / \mathrm{M}$ method for obtaining desirable surface properties. The influence of following parameters, i.e., material of $\mathrm{P} / \mathrm{M}$ electrode, its particle size, compaction pressure and sintering temperature on machined surface are usually of interest for advancement of research in this field. The literature available in this area is mostly concentrated on studying the influence of above parameters on surface modification process. The surfaces machined with $\mathrm{P} / \mathrm{M}$ electrodes successfully improved the hardness, wear resistance, fatigue resistance, corrosion resistance etc., but finally the improvement was obtained, not without the sacrifice of surface roughness. Few published literatures is presented here for quick reference. Khan et al. [12] machined mild steel material using $\mathrm{TiC} / \mathrm{Cu} \mathrm{P} / \mathrm{M}$ material and obtained roughness value in the range of 5.772$14.782 \mu \mathrm{m}$. Gill and Kumar [13] machined H11 hot die steel by machining with $\mathrm{Mn}-\mathrm{Cu} \mathrm{P} / \mathrm{M}$ electrode and obtained roughness value in the range of 3.27.5 $\mu \mathrm{m}$. Rahang and Patowari [14] machined aluminium alloy with a $\mathrm{W}-\mathrm{Cu} \mathrm{P} / \mathrm{M}$ electrode and obtained the roughness in the range extending from 4.5 to $9.5 \mu \mathrm{m}$. It is concluded from the available literature that due to loosely bonded particles in P/M electrodes, the roughness of the EDMed surface is higher than the surface machined with single solid material [15] and this roughness value further increases with the increase in particle size of $\mathrm{P} / \mathrm{M}$ electrode. Average particle sizes used in making some of the P/M electrodes in their research are as follows: $\mathrm{Li}$ et al., used $23 \mu \mathrm{m}$ size of $\mathrm{Cu}-\mathrm{W}$ powder

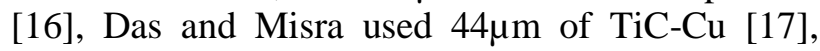
Cogun et al., used $70 \mu \mathrm{m}$ of $\mathrm{Cu}-\mathrm{B}_{4} \mathrm{C}$ [18], Singh and banwait [19] machined AISI 1045 die steel using $\mathrm{Cu} / \mathrm{Cr} \mathrm{P} / \mathrm{M}$ electrode and obtained a minimum surface roughness of $6.19 \mu \mathrm{m}$, Bai and Koo used $15 \mu \mathrm{m}$ Al-Mo [20] etc. So, it is observed that the average particle size used for making P/M electrodes were within the micron range. But the particle size of $\mathrm{P} / \mathrm{M}$ electrode has shown its greatest effect on the properties of EDMed surface [20] and the available literature in this area is very limited. Small particle size (fine particle) is one of the basic requirements for liquid phase sintering [21] and also for obtaining lower roughness of the EDMed surface. Particle size of the $\mathrm{P} / \mathrm{M}$ electrode is also important for the process stability of EDM [22]. With the increase in particle size, chances for short circuiting increases, which reduces the process stability, hence the machining efficiency. Apart from the tool parameters, setting of machining parameters was also proved to be important in obtaining better mechanical properties of EDMed surface as it is dependent on tool parameters. The present investigation is the study of surface modification of Inconel 718 as it plays an important role in improving the hardness, wear and corrosion resistance of the component but it adversely affects surface roughness. The particle size is expected to play an important role in obtaining the improved surface roughness along with improvement in mechanical and chemical properties of the EDMed surface. There is a dearth of information about the influence of particle size on EDMed surface when machined with powder metallurgy (P/M) electrode. With the best of the author's knowledge not much work was reported on the effects of the particle size of $\mathrm{P} / \mathrm{M}$ electrode on surface roughness and mechanical properties. Especially, it hasn't fully explored the influence of P/M electrode on surface modification when the particle size is reduced to nano level. 


\section{Experimentation}

\subsection{Selection of parameters and experiments}

Experiments were planned as per L18 $\left(2^{1} \times 3^{5}\right)$ mixed orthogonal array (OA) with 6 parameters, in which, one parameter is 2-level and remaining five parameters are 3-levels. The parameters which were selected under the study consist of tool and process parameters viz., polarity, peak current, pulse on time, particle size, \%WC and compaction pressure. The selected parameters and their levels, units and symbols are presented in Table 1. The experiments were conducted on die sinking EDM of Model S25 in Sparkonix (I) Pvt. Ltd., Pune, India and the experimental setup can be seen in Fig. 1. The dielectric used in these experiments is EDM oil. The experiments were conducted on Inconel 718 with sintered $\mathrm{WC} / \mathrm{Cu}$ electrodes and the surface roughness and hardness of each sample was measured. The surface roughness measurements were conducted using Taylor Hobson Talysurf 120 L (cut-off length of $0.8 \mathrm{~mm}$, evaluation length of $4 \mathrm{~mm}$ ) and Micro hardness tests were conducted on Vickers digital micro hardness tester, DHV-1000, with a load of 2.94 $\mathrm{N}(300 \mathrm{~g})$. For each experiment, five readings at different places on the surface were measured and the average was recorded. The surface roughness and hardness values of received Inconel 718 workpiece were found to be $3.38 \mu \mathrm{m}$ and $462 \mathrm{HV}$ respectively. The experimental results were analyzed with the help of images obtained from scanning electron microscope (SEM) and x-ray diffraction (XRD) techniques. The chemical composition of received and machined workpiece material was tested using JEOL JSM 6610LV SEM and the intermetallic phases generated during machining is identified with $\mathrm{X}$-pert pro materials research diffraction (MRD) system.

\subsection{Fabrication of $\mathrm{WC} / \mathrm{Cu}$ Electrodes}

The electrodes are made of electrolytic copper $(\mathrm{Cu})$ and Tungsten carbide (WC) powders with $99.9 \%$ pure (Powder materials are supplied by Nanoshel LLC, USA) and mixed at various weight proportions. The particle sizes used for making electrodes are in the range of 20 to $40 \mathrm{~nm}$ (nano size) and 30 to $50 \mu \mathrm{m}$ (micron size). Hereafter, the electrodes made with nano and micron sized powders are called as "NP electrode" and "MP electrode" respectively. The electrode made with a mix of nano and micron powders (equal wt.\%) is referred to as "NMP electrode." Mortal and pastel method is used for mixing the powder and liquid wax (1\% of total weight). Here, liquid wax is used as bonding agent and the mixing process is carried out for 30 minutes. The powder particles are then compacted at three different pressure settings i.e., 200, 300 and 400MPa in a cylindrical shaped die of $15 \mathrm{~mm}$ diameter and $50 \mathrm{~mm}$ length using 200T universal compression testing machine. The green compacts are sintered in a vacuum furnace by increasing the temperature gradually from room temperature to $350^{\circ} \mathrm{C}$ at the rate of $5^{0} \mathrm{C} / \mathrm{min}$. It is exposed for 30 minutes at that temperature. The temperature is further increased to $950^{\circ} \mathrm{C}$ at the rate of $10^{\circ} \mathrm{C} / \mathrm{min}$ and is held for 60 minutes at the peak temperature in an argon gas environment. The sintered components are furnace cooled with a rate of $5^{0} \mathrm{C} / \mathrm{min}$ i.e., approximately 3.5 hours to avoid cracking. The prepared electrodes are then attached to brass rods of $12 \mathrm{~mm}$ diameter and $50 \mathrm{~mm}$ length with the help of electrically conductive adhesive.

\subsection{Suitability of WC/Cu Electrodes for EDM}

The major properties which determine the suitability of $\mathrm{WC} / \mathrm{Cu}$ electrodes are its density and electrical conductivity. Density of EDM sintered electrodes and electrical conductivity is measured using the Archimedes water immersion principle and ohmmeter respectively. The variation in density and electrical conductivity with respect to tool parameters viz., particle size, \%WC composition and compaction pressure are recorded and presented in Fig. 2. When the particle size is reduced to a nano scale, porosity reduces and it enhances the properties such as density and thermal conductivity. In $\mathrm{WC} / \mathrm{Cu}$ composite tool electrode, at higher wt.\% of WC (density of WC is very high when compared to $\mathrm{Cu}$ ), the electrode becomes denser, this certainly improves the thermal conductivity of the electrode.

Similarly, when the compaction pressure increases, it increases the packing density of green compact resulting increased thermal conductivity. It is observed that higher values of density and electrical conductivity are obtained when a particle size is reduced to nano scale, i.e., for NP electrode, at $60 \% \mathrm{WC}$ and at $400 \mathrm{MPa}$, both being the highest values of wt.\% and compaction pressure respectively. The lowest and highest values for density and electrical conductivity at all combinations were found to be in the range of 6.82 to $9.75 \mathrm{~g} / \mathrm{cm}^{3}$ and 53.57 to $74.75 \mathrm{~S} / \mathrm{m}$ respectively. The above values are fairly good and within the working range for 
obtaining the stable spark during machining. This implies that the sintered electrodes of $\mathrm{WC} / \mathrm{Cu}$ are suitable for EDM.

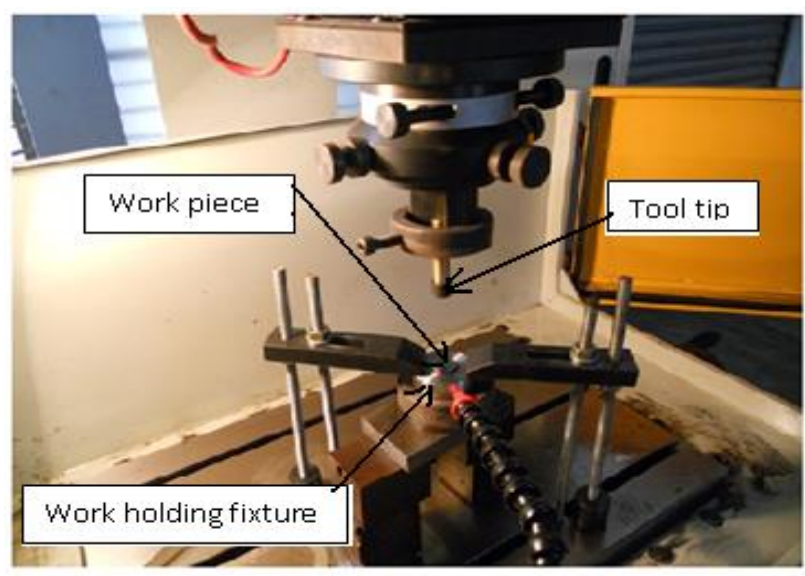

Figure 1. EDM machine tool with P/M electrodes and work holding devices

\section{Results and discussion}

The Signal/Noise $(\mathrm{S} / \mathrm{N})$ ratio analysis is conducted using the Taguchi's method in order to find the optimal parameter settings for surface roughness (SR) and micro-hardness (MH). This can be calculated as a logarithmic transformation of the loss function and the characteristics selected for SR and $\mathrm{MH}$ are "Lower is better" and "Higher is better" respectively as given in equations (1) and (2). Here, ' $y$ ' is the individual measured response value and ' $n$ ' is the number of measurements.

S/N ratio for Surface Roughness

$$
\eta=-10 \log \frac{1}{\mathrm{n}} \sum_{\mathrm{i}=1}^{\mathrm{n}} \mathrm{y}^{2}
$$

S/N ratio for Hardness

$$
\eta=-10 \log \frac{1}{\mathrm{n}} \sum_{\mathrm{i}=1}^{\mathrm{n}}\left(\frac{1}{\mathrm{y}^{2}}\right)
$$

The experimental results of SR and $\mathrm{MH}$ and their corresponding $\mathrm{S} / \mathrm{N}$ ratios are given in Table 2. Mean $\mathrm{S} / \mathrm{N}$ ratio at each level of the experimental data for all the six parameters has been calculated and presented in Table $3 \& 4$ for both SR and MH respectively. The difference between two extreme values of $\mathrm{S} / \mathrm{N}$ ratios is calculated and represented with "Delta." The factor for which highest delta value is obtained is ranked as
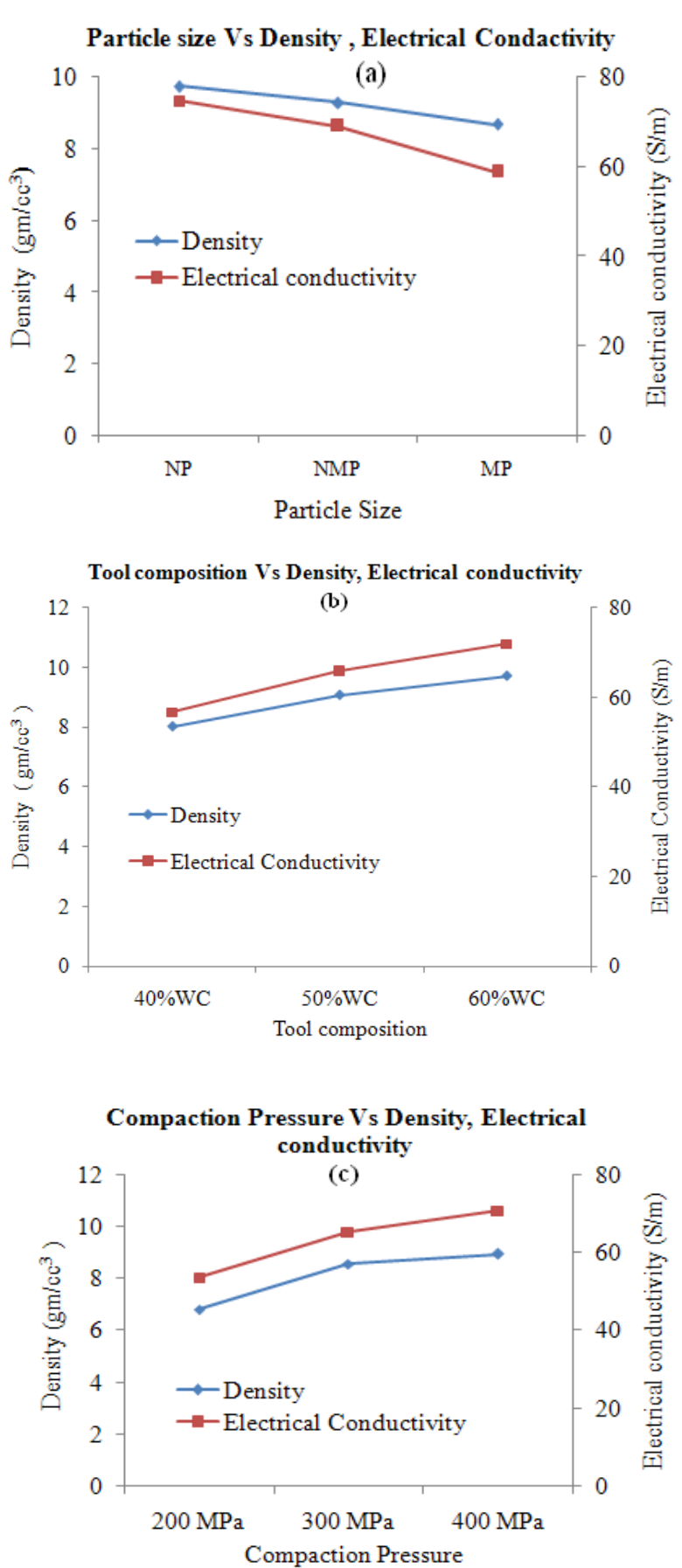

Figure 2. The variation of density and electrical conductivity of $P / M$ electrodes on (a) Particle size, (b) \%WC and (c) Compaction pressure

1 and so on. Irrespective of the characteristics, the level at which higher $\mathrm{S} / \mathrm{N}$ ratio is obtained represents better performance. This level is called the optimal level. The optimal levels of SR and MH are presented in Figs. $3 \&$ 4, respectively. The optimal machining combination for better surface roughness is obtained using positive polarity (A1), lower level of peak 
Table 1. Parameters and their levels

\begin{tabular}{|l|c|c|c|c|}
\hline \multicolumn{1}{|c|}{ Parameters } & Symbol & Level 1 & Level 2 & Level 3 \\
\hline Electrode polarity & POL & Positive (P) & Negative (N) & -- \\
\hline Peak current $(\mathrm{Amp})$ & IP & 7 & 10 & 13 \\
\hline Pulse on time $(\mu \mathrm{sec})$ & TON & 4 & 8 & 12 \\
\hline Particle Size & PS & $\begin{array}{c}\text { NP } \\
(\text { Nano) }\end{array}$ & $\begin{array}{c}\text { NMP } \\
\text { Mano and } \\
\text { Micron mix })\end{array}$ & $\begin{array}{c}\text { MP (Micr } \\
\text { on) }\end{array}$ \\
\hline \% WC in WC/Cu tool electrode & \%WC & 40 & 50 & 60 \\
\hline Compaction Pressure (MPa) & CP & 200 & 300 & 400 \\
\hline
\end{tabular}

Table 2. Experimental results and $S / N$ ratios of $S R$ and $M H$

\begin{tabular}{|c|c|c|c|c|c|c|c|c|c|c|}
\hline \multirow[b]{2}{*}{ S.No } & \multirow[b]{2}{*}{ POL } & \multirow[b]{2}{*}{ IP } & \multirow[b]{2}{*}{ TON } & \multirow[b]{2}{*}{ PS } & \multirow[b]{2}{*}{$\% \mathrm{WC}$} & \multirow[b]{2}{*}{$\mathbf{C P}$} & \multicolumn{2}{|c|}{ SR } & \multicolumn{2}{|c|}{ MH } \\
\hline & & & & & & & $\begin{array}{c}\text { Mean } \\
\text { SR }(\mu \mathrm{m})\end{array}$ & $\begin{array}{l}\mathrm{S} / \mathrm{N} \\
(\mathrm{dB})\end{array}$ & $\begin{array}{c}\text { MeanMH } \\
(\mathrm{HV})\end{array}$ & $\begin{array}{l}\mathrm{S} / \mathrm{N} \\
(\mathrm{dB})\end{array}$ \\
\hline 1 & $\mathrm{P}$ & 7 & 4 & NP & 40 & 200 & 2.443 & -7.76 & 625 & 55.92 \\
\hline 2 & $\mathrm{P}$ & 7 & 8 & NMP & 50 & 300 & 3.009 & -9.57 & 554 & 54.87 \\
\hline 3 & $\mathrm{P}$ & 7 & 12 & MP & 60 & 400 & 3.210 & -10.13 & 501 & 54.00 \\
\hline 4 & $\mathrm{P}$ & 10 & 4 & $\mathrm{NP}$ & 50 & 300 & 2.829 & -9.03 & 605 & 55.64 \\
\hline 5 & $\mathrm{P}$ & 10 & 8 & NMP & 60 & 400 & 2.667 & -8.52 & 562 & 54.99 \\
\hline 6 & $\mathrm{P}$ & 10 & 12 & MP & 40 & 200 & 4.098 & -12.25 & 673 & 56.56 \\
\hline 7 & $\mathrm{P}$ & 13 & 4 & NMP & 40 & 400 & 3.091 & -9.80 & 695 & 56.84 \\
\hline 8 & $\mathrm{P}$ & 13 & 8 & MP & 50 & 200 & 3.889 & -11.80 & 706 & 56.98 \\
\hline 9 & $\mathrm{P}$ & 13 & 12 & $\mathrm{NP}$ & 60 & 300 & 3.082 & -9.78 & 815 & 58.22 \\
\hline 10 & $\mathrm{~N}$ & 7 & 4 & MP & 60 & 300 & 2.663 & -8.51 & 517 & 54.27 \\
\hline 11 & $\mathrm{~N}$ & 7 & 8 & $\mathrm{NP}$ & 40 & 400 & 2.797 & -8.93 & 584 & 55.33 \\
\hline 12 & $\mathrm{~N}$ & 7 & 12 & NMP & 50 & 200 & 3.465 & -10.79 & 689 & 56.76 \\
\hline 13 & $\mathrm{~N}$ & 10 & 4 & NMP & 60 & 200 & 3.111 & -9.86 & 586 & 55.36 \\
\hline 14 & $\mathrm{~N}$ & 10 & 8 & MP & 40 & 300 & 4.041 & -12.13 & 601 & 55.58 \\
\hline 15 & $\mathrm{~N}$ & 10 & 12 & NP & 50 & 400 & 2.821 & -9.01 & 688 & 56.75 \\
\hline 16 & $\mathrm{~N}$ & 13 & 4 & MP & 50 & 400 & 3.341 & -10.48 & 582 & 55.30 \\
\hline 17 & $\mathrm{~N}$ & 13 & 8 & NP & 60 & 200 & 3.494 & -10.87 & 845 & 58.54 \\
\hline 18 & $\mathrm{~N}$ & 13 & 12 & NMP & 40 & 300 & 4.096 & -12.25 & 760 & 57.62 \\
\hline
\end{tabular}


Table 3. Mean S/N ratios for surface roughness

\begin{tabular}{|l|c|c|c|c|c|c|}
\hline Level & POL & IP & TON & PS & \%WC & CP \\
\hline 1 & -9.849 & -9.282 & -9.239 & -9.229 & -10.520 & -10.554 \\
\hline 2 & -10.314 & -10.133 & -10.303 & -10.132 & -10.113 & -10.210 \\
\hline 3 & & -10.828 & -10.701 & -10.882 & -9.610 & -9.479 \\
\hline Delta & 0.465 & 1.546 & 1.462 & 1.653 & 0.911 & 1.076 \\
\hline Rank & 6 & 2 & 3 & 1 & 5 & 4 \\
\hline
\end{tabular}

Table 4. Mean S/N ratios for micro-hardness

\begin{tabular}{|l|r|r|r|r|r|r|}
\hline Level & POL & IP & TON & PS & \%WC & CP \\
\hline 1 & 56.00 & 55.19 & 55.55 & 56.73 & 56.31 & 56.69 \\
\hline 2 & 56.17 & 55.81 & 56.05 & 56.07 & 56.05 & 56.03 \\
\hline 3 & & 57.25 & 56.65 & 55.45 & 55.90 & 55.53 \\
\hline Delta & 0.17 & 2.06 & 1.10 & 1.29 & 0.41 & 1.15 \\
\hline Rank & 6 & 1 & 3 & 2 & 5 & 4 \\
\hline
\end{tabular}

current (B1), lower level of pulse on time (C1), nano tool electrode (D1), higher level of \%WC (E3) and higher level of compaction pressure (F3). This combination produces lower value of surface roughness. The negative polarity of tool electrode (A2), higher levels of peak current (B3), higher level of pulse on time (C3), nano tool electrode (D1), lower level of \%WC (E1) and lower level of CP (F1) produces higher micro hardness. So, the optimal S/N ratios for surface roughness and micro hardness are $\mathrm{A}_{1} \mathrm{~B}_{1} \mathrm{C}_{1} \mathrm{D}_{1} \mathrm{E}_{3} \mathrm{~F}_{3}$ and $\mathrm{A}_{2} \mathrm{~B}_{3} \mathrm{C}_{3} \mathrm{D}_{1} \mathrm{E}_{1} \mathrm{~F}_{1}$ respectively. The reasons for optimal level of each parameter and its influence on SR and MH are discussed below.

1. Polarity: It is observed that positive polarity produces low surface roughness. The reason can be explained as follows, in positive polarity workpiece is anode and electrode is cathode. So discharge spot is at anode, hence very less amount of tool particles migrate towards the work surface resulting in low

SR. Whereas, in the reverse polarity, electrode is made as anode, so large discharge energy will be obtained at the tool surface, resulting in more amount of loosely bonded particles falling onto the surface. More deposition of particles means more surface alloying, leading to formation of hard intermetallic phases and hence increase in surface hardness.

2. Peak Current: Increase in peak current increases the discharge energy thereby generating deep craters on the surface. This results in increased surface roughness. At higher peak currents, tool erosion rate is also high, resulting in greater deposition of particles and alloying, thus increasing the hardness value.

3. Pulse on time: At lower values of TON, better surface roughness and at higher values of TON, higher hardness values were observed. Increased pulse on time increases the single pulse discharge energy resulting in higher cutting rate. So, it is difficult to escape the large debris generated between the gaps leading to deterioration of the surface quality. At the same time, it increases the surface alloying and hence hardness of the surface is increased.

4. Particle size: The composite electrode made with NP electrode has produced the lowest surface roughness and highest hardness. In EDM, the particle size should be less than the spark gap dimension for enhanced process stability, otherwise frequent arcing decreases the surface quality. This happened with the NMP and MP electrodes. With the increase in density of NP electrode, the amount of $\mathrm{WC}$ and $\mathrm{Cu}$ particles dropped from the electrode should decrease, but in the present investigation, increased material transfer is observed. This can be attributed to the fact that if the particle size is reduced to nanoscale, the reactive surface area is much higher than that of micron size particles [23-24]. Hence, more amount of material is eroded, leading to increased surface alloying and hardness. It is also known, that the hardness of nano sized particles are significantly higher than that of their corresponding micron sized particles [25]. This may be another reason for higher hardness of the work surface. 
5. \%WC composition: In $\mathrm{WC} / \mathrm{Cu}$ composite tool electrode, at higher wt.\% of WC (density of WC is very high when compared to $\mathrm{Cu}$ ), the electrode becomes denser, this certainly improves the thermal conductivity of the electrode. So the tool erosion rate/material deposition rate at $60 \mathrm{wt} . \%$ of WC is less when compared to the other tool compositions i.e., at 40 and $50 \mathrm{wt} \%$ of WC. In P/M electrodes, lower amount of material deposition leads to better roughness value. The converse is also true, i.e., use of lower wt.\% of $\mathrm{WC}$ in $\mathrm{WC} / \mathrm{Cu}$ electrode, decreases the conductivity of the tool electrode, leading to more amount of migration of tool elements. Hence, decreased surface cracks and improved hardness and wear resistance is observed.

6. Compaction pressure: It was observed that higher compaction pressures show lower roughness value and lower compaction pressures show higher hardness value. This can be explained by the fact that, at higher $\mathrm{CP}$, the tool becomes dense and the transfer of material towards the workpiece is lower, hence better surface roughness was observed. Whereas, at lower CP, loosely bonded particles of the tool doesn't withstand shock generated during machining, resulting in more amounts of material transfer onto the work surface. This results in increased surface alloying, thereby increasing hardness. Improved flushing of this debris in the form of bigger size particles creates arcing during machining resulting in degradation of the work surface. This may be the reason for obtaining higher roughness values at lower compaction pressures.

\subsection{Confirmation experiment}

The confirmation experiment is performed by conducting a test with a specific combination of factors and levels that are previously evaluated. In this study, after determining the optimum conditions, a new experiment is designed and conducted using the optimum levels of the machining parameters. The final step is to predict and verify the improvement of the performance characteristics. Equation (3) predicts the $\mathrm{S} / \mathrm{N}$ ratio using optimal levels of machining parameters in order to verify the improvements in performance characteristics [26].

$$
\eta_{\mathrm{opt}}=\eta_{\mathrm{m}}+\sum_{\mathrm{j}=1}^{\mathrm{k}}\left(\eta_{\mathrm{j}}-\eta_{\mathrm{m}}\right)
$$

" $\eta_{\text {opt }}$ " is the predicted optimal $\mathrm{S} / \mathrm{N}$ ratio, " $\eta_{\mathrm{m}}$ " is the total mean of the $\mathrm{S} / \mathrm{N}$ ratios, " $\eta_{\mathrm{j}}$ " is the mean $\mathrm{S} / \mathrm{N}$ ratio at the optimal levels and " $\mathrm{k}$ " is the number of main design parameters that affect the quality characteristics. The estimated optimal $\mathrm{S} / \mathrm{N}$ ratio $\left(\eta_{\mathrm{opt}}\right)$ for SR is -6.28 and the corresponding SR value is 2.06. This value is close to the experimental value of $2.13 \mu \mathrm{m}$, machined at same optimal conditions. Similarly, the estimated optimal $\mathrm{S} / \mathrm{N}$ ratio $\left(\eta_{\mathrm{opt}}\right)$ for $\mathrm{MH}$ is 59.37 and the corresponding $\mathrm{MH}$ is $930 \mathrm{HV}$. This value is close to the experimental value of $895 \mathrm{HV}$, machined at same optimal conditions.

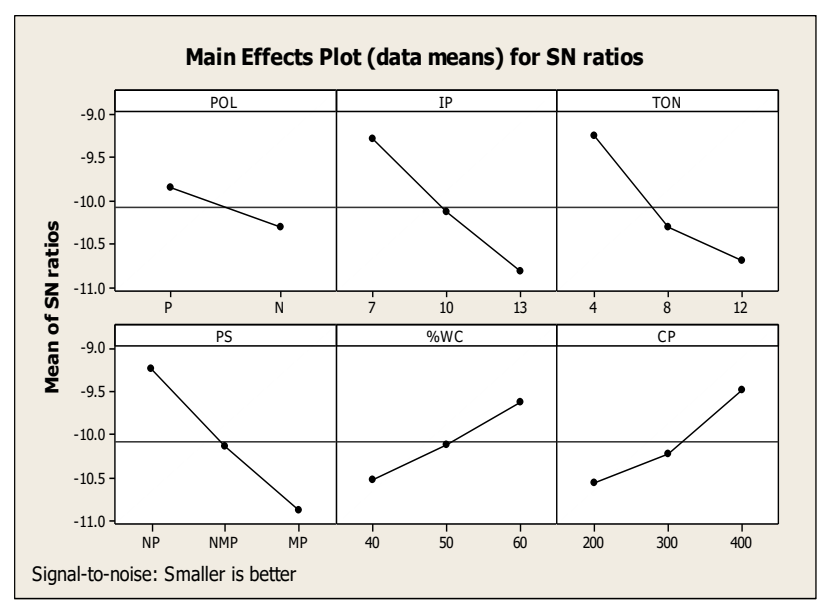

Figure 3. Main effect plots for surface roughness

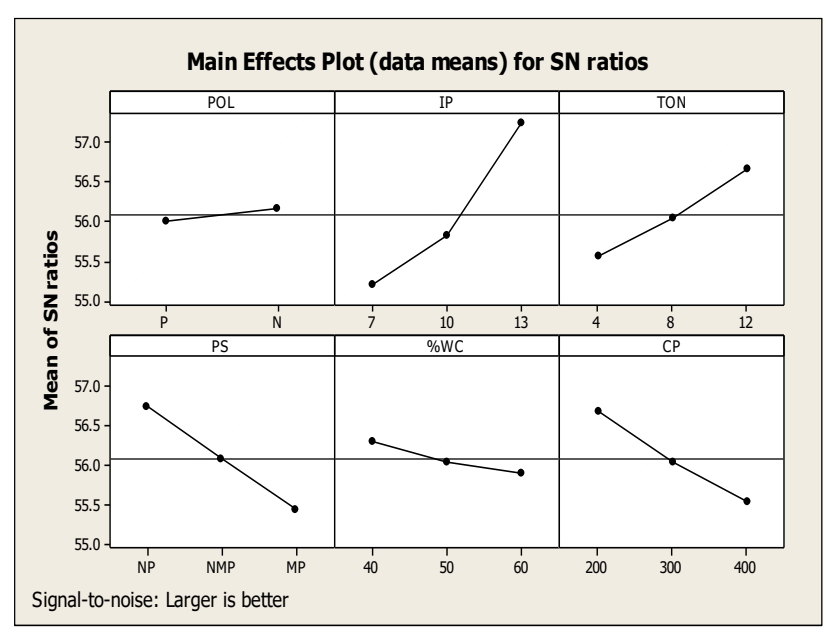

Figure 4. Main effect plots for Micro hardness

\subsection{Analysis of variance (ANOVA) for SR and MH}

ANOVA is performed to control variation of a process, since variation is a large part of discussion related to quality. The influence of each parameter on SR and MH can be estimated and evaluated in terms of percentage contribution. The results of ANOVA 
are presented in Tables $5 \& 6$ for SR and $\mathrm{MH}$ respectively. Confidence level of $95 \%(\alpha=0.05)$ is used in the analysis; for the parameter analysis, the pvalue which is less than 0.05 is considered as statistically significant on the performance measure. It is observed that particle size (25.79), is most significant parameter in controlling the variation followed by peak current, pulse on time, compaction pressure and \%WC, whereas polarity doesn't show any significant effect on the surface roughness. In the case of $\mathrm{MH}$, the parameter peak current (48.66\%) is found to be most significant followed by particle size, pulse on time and compaction pressure, whereas $\%$ WC and polarity are found to be insignificant on the performance measure of micro hardness. The parameters IP, PS, TON and CP are observed to be significant on both SR and MH. To investigate SR and $\mathrm{MH}$ in more detail, the work surfaces produced at optimum conditions and as received work pieces are used for further experimental analysis, viz., micro structural analysis using SEM, chemical analysis using EDX, phase analysis using XRD on the above surfaces and are presented below.

Table 5. Analysis of variance for surface roughness

\begin{tabular}{|c|c|c|c|c|c|c|c|}
\hline Source & DF & Seq.SS & Adj.SS & Adj.MS & F & P & \%P \\
\hline POL & 1 & 0.12684 & 0.12684 & 0.12684 & 2.43 & 0.170 & 2.75 \\
\hline IP & 2 & 0.97526 & 0.97526 & 0.48763 & 9.35 & 0.014 & 21.15 \\
\hline TON & 2 & 0.97042 & 0.97042 & 0.48521 & 9.31 & 0.014 & 21.05 \\
\hline PS & 2 & 1.18898 & 1.18898 & 0.59449 & 11.40 & 0.009 & 25.79 \\
\hline \%WC & 2 & 0.45611 & 0.45611 & 0.22806 & 4.37 & 0.067 & 9.89 \\
\hline CP & 2 & 0.5802 & 0.58020 & 0.29010 & 5.56 & 0.043 & 12.58 \\
\hline Error & 6 & 0.31283 & 0.31283 & 0.05214 & & & \\
\hline Total & 17 & 4.61065 & & & & & \\
\hline
\end{tabular}

Table 6. Analysis of variance for micro hardness

\begin{tabular}{|c|c|c|c|c|c|c|c|}
\hline Source & DF & Seq.SS & Adj.SS & Adj.MS & F & P & \%P \\
\hline POL & 1 & 748 & 748 & 748 & 0.58 & 0.475 & 0.47 \\
\hline IP & 2 & 77992 & 77992 & 38996 & 30.23 & 0.001 & 48.66 \\
\hline TON & 2 & 22216 & 22216 & 11108 & 8.61 & 0.017 & 13.86 \\
\hline PS & 2 & 28296 & 28296 & 14148 & 10.97 & 0.010 & 17.65 \\
\hline \%WC & 2 & 1419 & 1419 & 710 & 0.55 & 0.603 & 0.89 \\
\hline CP & 2 & 21874 & 21874 & 10937 & 8.48 & 0.018 & 13.65 \\
\hline Error & 6 & 7740 & 7740 & 1290 & & & \\
\hline Total & 17 & 160285 & & & & & \\
\hline
\end{tabular}

\subsection{Surface roughness (SR)}

The machining conditions for best SR are positive polarity, low peak current $\&$ pulse on time, higher wt.\% of WC, NP electrode and higher compact pressure. The SEM images at optimum machining conditions can be seen in Fig. 5(a) and (b) respectively, where lowest surface roughness and highest micro hardness values were observed respectively. At optimum machining conditions of $\mathrm{SR}$, the surface shows narrow pocks and uniform rippled surfaces whereas wider and deeper machined pocks and non-uniform rippled surfaces were observed at optimum conditions of MH. Fig. 6 (a) shows the as received material of EDS spectrum and Figs. 6(b) \& (c) shows the spectrum obtained for surfaces machined at optimal SR and MH conditions respectively. The chemical compositions of received and machined surfaces are given in Table 7 . From the table, it is observed that $16.4 \mathrm{wt} \%$ of $\mathrm{Cr}, 0.00 \mathrm{wt} \%$ of $\mathrm{W}, 0.27 \mathrm{wt} \%$ of $\mathrm{Cu}, 3.03 \mathrm{wt} \%$ of $\mathrm{O}$ and other elements $(\mathrm{Nb}, \mathrm{Ni}, \mathrm{Fe}$, and $\mathrm{C})$ confirms that, the as received 
material as Inconel 718. When compared to received material, the increase in $\mathrm{W}$ and $\mathrm{Cu}$ wt.\% at all the machining conditions show the migration of tool elements from tool to work surface. The reduction in $\mathrm{Ni}, \mathrm{Fe}$ and Mo wt\% on EDMed surface is due to relative increase in other elements like $\mathrm{W}, \mathrm{Cr}, \mathrm{Cu}, \mathrm{C}$ and $\mathrm{O}$. Rich amount of carbon deposited on the machined surface is due to pyrolysis of EDM oil.
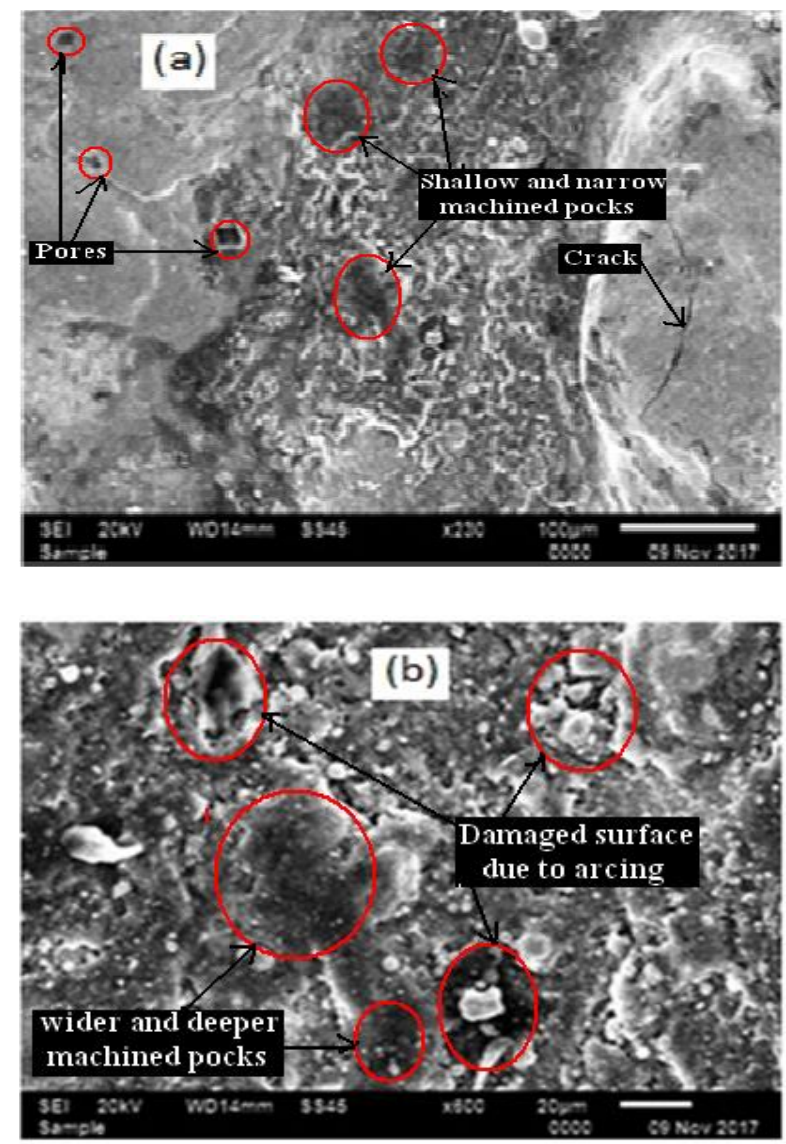

Figure 5. (a) SEM image at optimal surface roughness and (b) at optimal micro hardness condition.

Increase in oxygen element indicates the effect of oxidation due to high temperature machining. The variation in chemical composition of EDMed surface indicates the variation due to machining and tool parameters. Machining parameters affect the discharge energy and tool parameters affect the tool properties and both in turn affect the machined surface. The positive polarity machining helps in reducing the amount of particles transferred to the work surface. In P/M electrodes, the particles are held together by weakly bonded particles. Positive polarity produces the discharge spot at work surface rather than at tool surface and so it reduces the migration of tool elements towards the work surface. The surface alloying/modification happen in EDM due to migration of particles often producing rougher surfaces. In the present case, due to the reduction in particle size to nano scale, surface roughness of work piece is reduced significantly.
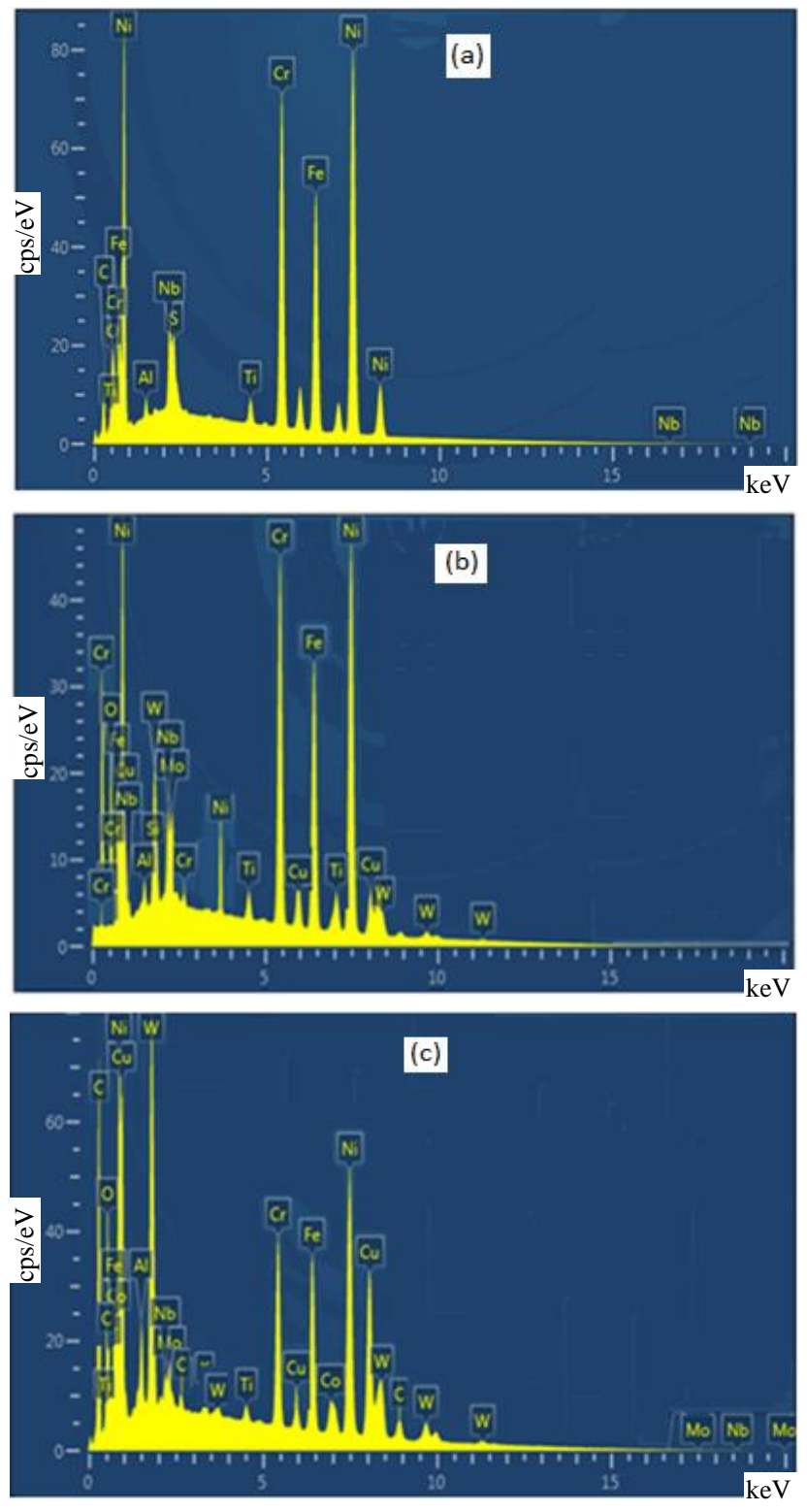

Figure 6. EDS plot of surface obtained for (a) as received Inconel 718 super alloy $(b)$ at optimum conditions of surface roughness and (c) at optimum conditions of micro hardness

Lower roughness at optimum machining conditions can be attributed to lower values of TON and IP, resulting low discharge energies, thus decreasing 
Table 7. Chemical composition of received and EDMed Inconel 718 alloy

\begin{tabular}{|l|c|c|c|}
\hline \multirow{2}{*}{ Elements } & \multicolumn{3}{|c|}{ Chemical composition in Wt\% } \\
\cline { 2 - 4 } & $\begin{array}{c}\text { As received } \\
\text { Material } \\
\text { Inconel 718 }\end{array}$ & $\begin{array}{c}\text { At optimum } \\
\text { Machining condition } \\
\text { of SR }\end{array}$ & $\begin{array}{c}\text { At optimum } \\
\text { Machining condition } \\
\text { of MH }\end{array}$ \\
\hline Nickel & 42.2 & 35.2 & 33.3 \\
\hline Ferrous $(\mathrm{Fe})$ & 17.2 & 7.2 & 9.6 \\
\hline Chromium(Cr) & 16.4 & 14.9 & 8.7 \\
\hline Carbon $(\mathrm{C})$ & 12.5 & 14.3 & 15.1 \\
\hline Copper(Cu) & 0.27 & 8.2 & 11.4 \\
\hline Niobium(Nb) & 4.0 & 2.4 & 1.0 \\
\hline Oxygen $(\mathrm{O})$ & 3.03 & 4.3 & 6.4 \\
\hline Molybdenum(Mo) & 3.0 & 1.6 & 1.3 \\
\hline Titanium $(\mathrm{Ti})$ & 0.9 & 0.5 & 0.3 \\
\hline Aluminium $(\mathrm{Al})$ & 0.5 & 0.3 & 0.3 \\
\hline Tungsten(w) & -- & 11.1 & 12.6 \\
\hline
\end{tabular}

crater size. From the Table 7, it is observed that lower wt $\%$ of elements viz., $\mathrm{Cu}-8.2, \mathrm{~W}-11.1, \mathrm{C}-14.3$ and $\mathrm{O}-$ 4.3 , at optimum conditions indicate the lower discharge energies generated during machining. The lower value of white layer thickness $\sim 198 \mu \mathrm{m}$ can be seen in Fig. 7, which indicates the low dischargeenergy conditions at optimum SR machining condition. The properties of tool electrode viz., electrical conductivity and density play an important role in obtaining the surface roughness.

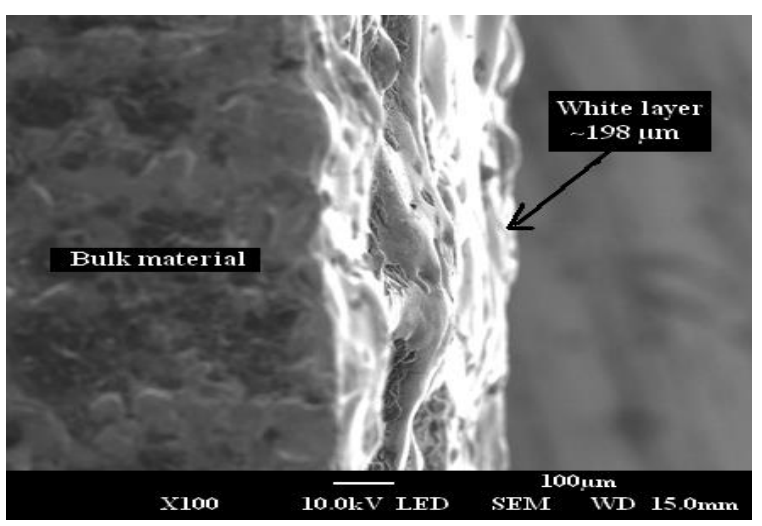

Figure 7. White layer thickness at optimum surface roughness conditions

The thermal conductivity of denser NP electrodes is higher than that of the NMP and MP electrodes. The increase in thermal conductivity reduces the amount of material migration hence reducing the surface
The XRD image in Fig. 8 shows formation of tungsten trioxide $\left(\mathrm{WO}_{3}\right)$ phase, which indicates the low and less time of diffusion of oxygen atoms into the metal due to low discharge energies at optimum SR conditions. The formation of "Hagg carbide" $\left(\mathrm{Fe}_{5} \mathrm{C}_{2}\right)$ and ferrous carbide $(7 / 3)$ and $(5 / 2)\left(\mathrm{Fe}_{7} \mathrm{C}_{3}\right.$ and $\mathrm{Fe}_{5} \mathrm{C}_{2}$ ) which generally forms at lower temperatures in that series may also show the low discharge energies. The use of higher compaction pressures in optimum SR conditions makes the surface smoother.

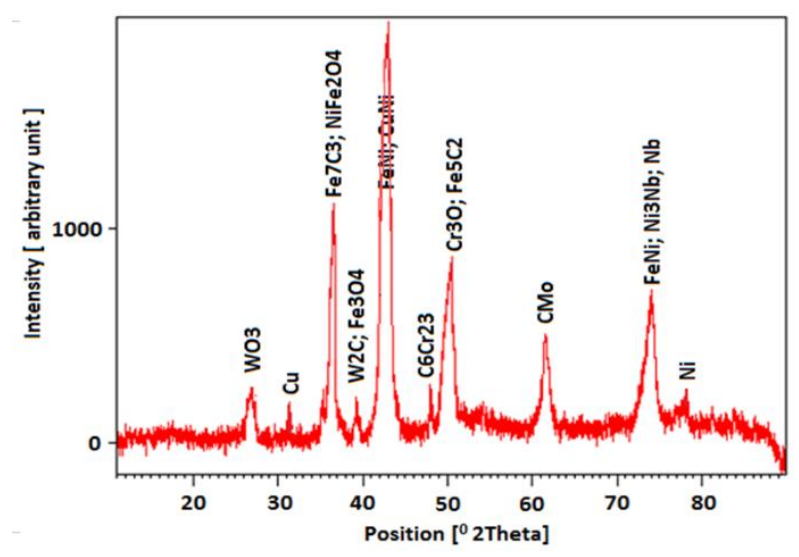

Figure 8. XRD pattern of EDMed surface at optimum surface roughness conditions

The use of NP electrode makes the particle size smaller than the spark gap dimension, reducing arcing and short circuiting thereby improving the process stability. Hence surface roughness is reduced [27-28]. 
The surface roughness values produced using $\mathrm{P} / \mathrm{M}$ electrodes in the past research are slightly higher. Though the machining conditions were different, the surface roughness values obtained in the present investigation are much lower than the results presented in the earlier research.

\subsection{Hardness test}

Hardness values for the surfaces machined by varying machine and tool parameters are given in Table 2. The machining conditions for best $\mathrm{MH}$ are negative polarity of the tool, higher levels of TON and IP, NP electrode, lower level of \%WC and lower level of compaction pressure. Because of particles being reduced to nano level, a large capillary force is generated in the rearrangement stage of liquid phase sintering leading to denser electrodes. So, density of NP electrode is higher when compared to NMP and MP electrodes. Hence, the tool particles are strongly held together and the tool erosion rate is reduced. Despite that, higher reactive surface area of nano particles makes the particles erode faster than the other electrodes. Hence, surface alloying capability is more with nano tools resulting in improved microhardness. From the experimental data, observed higher hardness value is $845 \mathrm{HV}$ at trial 17 ; this is slightly lower than the optimum $\mathrm{MH}$ value of $895 \mathrm{HV}$. High discharge energies due to higher values of IP and TON contribute for obtaining increased values of $\mathrm{MH}$. This results in increased white layer thickness of $\sim 278 \mu \mathrm{m}$, observed in the Fig. 9 at optimum machining condition for $\mathrm{MH}$. The chemical composition for optimum $\mathrm{MH}$ given in Table 7 clearly indicates the significant transfer of tool elements ( $\mathrm{W}$ and $\mathrm{Cu}$ ), diffusion of oxygen and deposition of rich amount of carbon due to pyrolysis of dielectric [29].

Fig. 10 shows the EDS spectrum for the machined component at optimum $\mathrm{MH}$ conditions. The high $\mathrm{MH}$ can be attributed to the availability of carbon and oxygen elements leading to the formation of various carbides and oxides. The following carbides, oxides and other intermetallics are responsible for increase in hardness viz., tungsten carbides ( $\mathrm{WC}$ and $\mathrm{W}_{2} \mathrm{C}$ ), Molybdenum carbide (CMo), tungsten tri-oxide $\left(\mathrm{WO}_{3}\right)$ and other intermetallics Niobium-Nickel $\left(\mathrm{Ni}_{3} \mathrm{Nb}\right)$, Iron Niobium $\left(\mathrm{Fe}_{2} \mathrm{Nb}\right)$ and Nickel $(\mathrm{FeNi})$. The transformation of "Hagg carbide" $\left(\mathrm{Fe}_{5} \mathrm{C}_{2}\right)$ into cementite $\left(\mathrm{Fe}_{3} \mathrm{C}\right)$ is also responsible for higher values of hardness at optimum conditions. Low $\mathrm{CP}$ values made more amount of material transfer from tool to work surface possible.

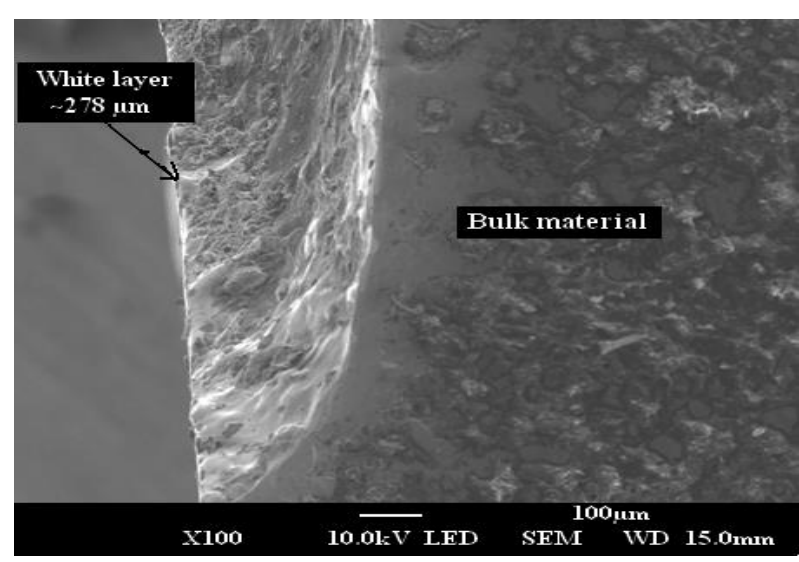

Figure 9. White layer thickness at optimum micro hardness machining conditions

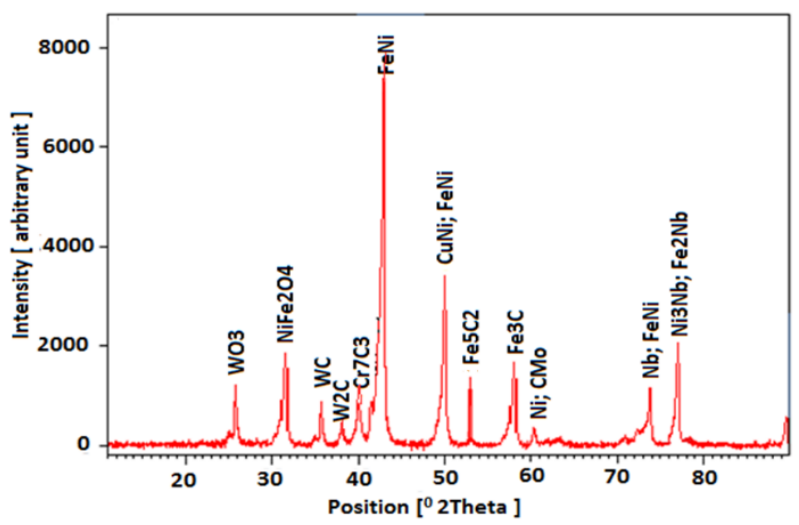

Figure 10. XRD pattern of EDMed surface at optimum micro hardness conditions

\section{Conclusions}

The present study is aimed at improving the surface properties of Inconel 718 using $\mathrm{WC} / \mathrm{Cu}$ composite electrode. From the experimental results the following conclusions are made.

a. The experimental analysis shows that IP, TON, PS and CP have significantly influenced SR and MH. The parameters, polarity on SR, polarity \& $\% \mathrm{WC}$ on MH do not show any influence.

b. At optimal combinations of parameters the SR and $\mathrm{MH}$ values obtained are $2.13 \mu \mathrm{m}$ and $895 \mathrm{HV}$, respectively. The use of NP electrodes in the present study has considerably reduced the SR values when compared to other $\mathrm{P} / \mathrm{M}$ electrodes made with micron size particles.

c. Surface modification of Inconel 718 was successfully carried out by using $\mathrm{WC} / \mathrm{Cu} \mathrm{P} / \mathrm{M}$ 
electrode. Because of the high reactive surface area of the nano particles, NP electrodes promoted greater surface alloying than the NMP and MP electrodes. Hence, better surface roughness and improved hardness values were obtained concurrently.

d. EDS of the machined surface confirms the increased $\mathrm{wt} \%$ of $\mathrm{W}, \mathrm{Cu}, \mathrm{C}$, and $\mathrm{O}$ elements at both the optimal combinations for SR and MH, when compared to as received material. Higher concentration of these elements was observed on the surface machined at optimal combination of MH than the SR. Furthermore, these elements are found in the form of carbides, oxides and other intermetallic phases.

e. Small craters, uniform ripples and thin uniform WLT of $\sim 198 \mu \mathrm{m}$ and hence best surface quality was obtained at low discharge energies. The white layer thickness at optimum $\mathrm{MH}$ is $\sim 278 \mu \mathrm{m}$, this being relatively higher. But reduced particle size and increased material deposition resulted in the surface having fewer micro cracks.

f. Though, the NP electrode promoted more material transfer, due to a particle size being smaller than the spark gap dimension, chances of arcing and short circuiting was reduced, hence surface roughness is improved. A good quality surface significantly improves the mechanical and chemical properties of the component, hence it is expected to increase the industrial applications.

g. The formation of carbides $\left(\mathrm{WC}, \mathrm{W}_{2} \mathrm{C}, \mathrm{Cr}_{7} \mathrm{C}_{3}\right.$, $\mathrm{Fe}_{5} \mathrm{C}_{2}$ and $\left.\mathrm{Fe}_{3} \mathrm{C}\right)$ and oxides $\left(\mathrm{WO}_{3}, \mathrm{Cr}_{3} \mathrm{O}, \mathrm{Fe}_{3} \mathrm{O}_{4}\right.$ and $\mathrm{NiFe}_{2} \mathrm{O}_{4}$ ) and other intermetallic phases (CMo, $\mathrm{FeNi} \mathrm{Ni}_{3} \mathrm{Nb}$ and $\mathrm{Fe}_{2} \mathrm{Nb}$ ) are responsible for increased hardness at optimal conditions. At optimum $\mathrm{MH}$, higher values of TON and IP provide sufficient time and temperature for transformation of $\mathrm{Fe}_{5} \mathrm{C}_{2}$ to $\mathrm{Fe}_{3} \mathrm{C}$. The $\mathrm{Cu}$ element which is transformed from the tool material is in the form of $\mathrm{CuNi}$ and free $\mathrm{Cu}$. The increased hardness and presence of copper element is expected to increase the wear and corrosion resistance of the component respectively.

h. Sintering parameters are to be carefully studied in order to control the grain size of the electrodes and the use of nano particles is slightly expensive. However, in applications where the situation demands for quality products, the used NP electrodes can be justified. This work can be extended for studying of other parameters in the surface integrity.

\section{Acknowledgements}

The authors are thankful to the management of GITAM (Deemed to be University), Visakhapatnam, India for allowing us to utilize the equipment purchased under DST-SERB project.

\section{References}

[1] Wang, F., Liu, Y, H., Shen, Y., Ji, R, J., Tang, Z, M., Zhang, Y, Z.: Machining performance of Inconel 718 using high current density electrical discharge milling, Materials and Manufacturing Processes, 28 (2013) 10, 1147-1152.

[2] Li, L., Li, Z, Y., Wei, X, T., Cheng, X.: Machining Characteristics of Inconel 718 by Sinking-EDM and Wire-EDM, Materials and Manufacturing Processes, (2014), DOI: 10.1080/10426914.2014.973579

[3] Wang, S., Ma, Z., Liao, Z,H., Song, J., Yang, K.: Study on improved tribological properties by alloying copper to CP-Ti and Ti6Al4V alloy. Material Science and Engineering C, 57 (2015) 123-132.

[4] Luo, J., Ye, P., Li, M,Q., Liu, L, Y.: Effect of the alpha grain size on the deformation behaviour during isothermal compression of Ti6Al4V alloy, Material and Design, 88 (2015) 32-40.

[5] Arulkirubakaran, D., Senthilkumar, V., Kumawat, V.: Effect of micro-textured tools on machining of Ti6Al4V alloy, An experimental and numerical approach, International journal of Refractory Materials, 54 (2016), 165-117.

[6] Fitseva, V., Krohn, H., Hanke, S., Dos santos, J,F.: Friction surfacing of Ti6ALAV Process characteristics and deposition behaviour at various rotational speeds, Surface Coatings Technology, 278 (2015), 56-63.

[7] Chandramani, U., Saurav, D., Manoj, M., Mahapatra, S, S.: An experimental investigation emphasizing surface characteristics of electrodischarge -machined Inconel 601. Journal of Brazilian Society of Mechanical Sciences and Engineering, DOI 10.1007/s40430-016-0643-2 (2016).

[8] Gill, A, S., Kumar, S.: Surface alloying of H11 die steel by tungsten using EDM Process, International Journal of Advanced Manufacturing Technology, 78 (2015), 1585-1593.

[9] Tijo, D., Shilpi, Kumari., Manoj, M.: Hard and wear resistance TiC-composite coating on AISI 1020 steel using powder metallurgy tool by 
electro-discharge coating process. Journal of Brazilian Society of Mechanical Sciences and Engineering, DOI 10.1007/s40430-017-0851-4 (2017).

[10] Mahanta, S., Chandrasekaran, M., Samanta, S., Arunachalam, R,M.: EDM investigation of $A l$ 7075 alloy reinforced with $B 4 C$ and fly ash nanoparticles and parametric optimization for sustainable production. Journal of Brazilian Society of Mechanical Sciences and Engineering, 40, 263 https://doi.org/10.1007/s40430-0181191-8(0123(2018).

[11] Das, S.: Surface alloying of aluminium by $\mathrm{W}-\mathrm{Cu}$ $\mathrm{Cr}$ powder metallurgy tool electrode in EDM, International journal of latest research in engineering and technology, 2 (2016) 1-10.

[12] Khan, A, A., Ndaliman, M, B., Mohamad, U, A, K, B., Sulong, N, F, B., Zain, Z, M.: Surface quality produced in EDM with tungsten carbide and copper compacted electrodes. Advances in Materials Research, 1115, (2015) 24-28.

[13] Gill, A, S., Kumar, S.: Surface roughness and micro hardness evaluation for EDM with $\mathrm{Cu}-\mathrm{Mn}$ Powder Metallurgy tool, Materials and Manufacturing Processes, 31 (2016) 514-521.

[14] Rahang, M., Patowari, P, K.: Parametric Optimization for Selective Surface Modification in EDM Using Taguchi Analysis, Materials and Manufacturing Processes, 31 (2016) 422-431.

[15] Khanra, A, K., Sarkar, B, R., Bhattacharya, B., Pathak, L, C., Godkhindi, M, M.: Performance of ZrB2-Cu composite as an EDM electrode, Journal of Material Processing Technology, 183 (2007) $122-126$.

[16] Li, L., Wong, Y, S., Fuh, J, Y, H., Lu, L.: Effect of TiC in copper-tungsten electrodes on EDM performance, Journal of Material Processing Technology, 113 (2001), 563-567.

[17] Das, A., Misra, J, P.: Experimental investigation on surface modification of aluminum by electric discharge coating process using $\mathrm{TiC} / \mathrm{Cu}$ green compact tool electrode. Machining Science and Technology, 16 (2012), 601-623.

[18] Cogun, C., Esen, Z., Genc, A., Cogun, F., Akturk, $\mathrm{N}$.: Effect of powder metallurgy $\mathrm{Cu}-\mathrm{B}_{4}$ C electrodes on workpiece surface characteristics and machining performance of electric discharge machining, Journal of Engineering ManufacturePart B, 230 (2016) 2190-2203.

[19] Singh, H., Banwait, S, S.: Experimental Investigations of Surface Modification of AISI 1045 Die Steel by Electro Discharge Machining
American Journal of Mechanical engineering, 4 (2016) 4, 131-141.

[20] Bai, C, Y., Koo, C, H.: Effects of kerosene or distilled water as dielectric on electrical discharge alloying of super alloy Haynes 230 with Al-Mo composite electrode. Surface Coating technology, 200 (2006), 4127-4135.

[21] Srikanth, V., Upadhyaya, G, S.: Effect of tungsten particle size on the sintered properties of heavy alloys. Powder Technology, 39 (1984), 61-67.

[22] Samuel, M, P., Philip, P, K.: Powder metallurgy tool electrodes for electric discharge machining. International journal of Machine tools and Manufacture, 37 (1997), 1625-1633.

[23] Wang, W, F.: Effect of tungsten particle size and copper content on working behaviour of $\mathrm{W}-\mathrm{Cu}$ alloy electrodes during electro discharge machining. Powder Metallurgy, 40 (1997) 4, 295 300.

[24] Yanik, B., Agustos, H., Ipek, Y., Koyun, A., Uzunsoy, D.: Synthesis and Characterization of Aluminium Nanoparticles by Electric Are Technique. Arabian Journal of Science and Engineering, 38 (2013), 3587-3592.

[25] Fang, Z, Z., Wang, Xu., Ryu, T., Hwang, K, S., Sohn, H, Y.: Synthesis, sintering, and mechanical properties of nanocrystalline cemented tungsten carbide - A Review. International Journal of Refractory Metals and Hard Materials, 27 (2009), 288-299.

[26] Mohammadi, A., Tehrani, A, F., Emanian, E., Karimi, D.: A new approach to surface roughness and roundness improvement in wire electrical discharge turning based on statistical analysis, International Journal of Advanced Manufacturing Technology, 39 (2008), 64-73.

[27] Patowari, P, K., Saha, P., Mishra, P, K.: An experimental investigation of surface modification of $\mathrm{C}-40$ steel using $\mathrm{W}-\mathrm{Cu}$ powder metallurgy sintered compact tools in EDM. International Journal of Advanced Manufacturing Technology, 80 (2015), 343-360.

[28] Singh, B., Kumar, J., Kumar, S.: Optimization and surface modification in electrical discharge machining of AA 6061/SiCp composite using $\mathrm{Cu}$ $W$ electrode. Journal of Materials Design and Applications- Part L, 231 (2017) 3, 332-348.

[29] Gangadharudu, T., Gangopadhyay, S., Biswas, C, K.: Effect of powder-suspended dielectric on the EDM characteristics of Inconel 625. Journal of Materials Engineering and Performace, 25 (2016), 704-717. 